\title{
The loss of taste genes in cetaceans
}

\author{
Kangli Zhu ${ }^{1 \dagger}$, Xuming Zhou ${ }^{2+}$, Shixia Xu' ${ }^{1}$ Di Sun ${ }^{1}$, Wenhua Ren ${ }^{1}$, Kaiya Zhou ${ }^{1}$ and Guang Yang ${ }^{1 *}$
}

\begin{abstract}
Background: Five basic taste modalities, sour, sweet, bitter, salt and umami, can be distinguished by humans and are fundamental for physical and ecological adaptations in mammals. Molecular genetic studies of the receptor genes for these tastes have been conducted in terrestrial mammals; however, little is known about the evolution and adaptation of these genes in marine mammals.

Results: Here, all five basic taste modalities, sour, sweet, bitter, salt and umami, were investigated in cetaceans. The sequence characteristics and evolutionary analyses of taste receptor genes suggested that nearly all cetaceans may have lost all taste modalities except for that of salt.

Conclusions: This is the first study to comprehensively examine the five basic taste modalities in cetaceans with extensive taxa sampling. Our results suggest that cetaceans have lost four of the basic taste modalities including sour, sweet, umami, and most of the ability to sense bitter tastes. The integrity of the candidate salt taste receptor genes in all the cetaceans examined may be because of their function in $\mathrm{Na}^{+}$reabsorption, which is key to osmoregulation and aquatic adaptation.
\end{abstract}

Keywords: Cetacean, Taste genes, Pseudogenization, Molecular evolution

\section{Background}

Cetaceans, commonly known as whales, dolphins and porpoises, have a mysterious history of transition from land to water. Numerous phylogenetic studies based on morphological as well as molecular characteristics have suggested that Cetacea is an independent clade nested within the mammalian order Artiodactyla (reviewed in [1]). Molecular studies have dated modern cetaceans (including toothed and baleen whales) to have originated about 34 Mya (Million years ago) [2,3]. Subsequently, cetaceans developed a series of adaptations to fully aquatic environments (e.g., loss of limbs, shortening of the skull, loss of sebaceous glands, echolocation ability in Odontoceti, and baleen plate in Mysticeti) [1,4,5]. However, the genetic basis for the origin and adaptation of this group of species is far from clear. Several studies have shown that many loci in cetaceans have gone through adaptive evolution, suggesting that some cetacean organs evolved adaptively while others degenerated. For example, the membrane motor protein gene prestin, which is associated

\footnotetext{
* Correspondence: gyang@njnu.edu.cn

${ }^{\dagger}$ Equal contributors

'Jiangsu Key Laboratory for Biodiversity and Biotechnology, College of Life Sciences, Nanjing Normal University, Nanjing 210023, China

Full list of author information is available at the end of the article
}

with high-frequency hearing in vertebrates, was shown to undergo positive selection in echolocating dolphins [6-8], whereas the number of olfactory receptor family pseudogenes is significantly higher in cetaceans than in other mammals [9-12].

Five basic taste modalities, sour, sweet, bitter, salt, and umami, can be distinguished by humans and are fundamental for physical and ecological adaptations in mammals $[13,14]$. Among them, umami and sweet tastes are attractive and beneficial to animals' ingestion of proteinrich and nutritious food. Salt at low concentrations is an attractive taste and is associated with $\mathrm{Na}^{+}$reabsorption [15-18]. Bitter tastes can cause taste aversion, thus protecting mammals from ingesting toxic substances $[19,20]$. Sour tastes are unpleasant and can prevent the ingestion of unripe and decayed food resources [21]. The receptor genes of each taste modality have been identified in mammals. In particular, umami/sweet tastants are perceived by Tas1rs (taste receptor, type 1 receptors) belonging to the G-protein coupled receptor C subtype family. Tas1r1 or Tas1r2 are co-expressed with Tas1r3 to perceive umami or sweet tastants, respectively [22-27]. Bitter substances are perceived by Tas2rs (taste receptor, type 2 receptors) [28-30]. Chandrashekar et al. (2000) [29] demonstrated that a mouse $\mathrm{T} 2 \mathrm{R}$ (mT2R-5) responded to the bitter 
tastant cycloheximide, and a human receptor hT2R-4 and a mouse receptor mT2R-8 responded to denatonium and 6-n-propyl-2-thiouracil. Jiang et al. (2012) [31] identified only 10 Tas $2 r s$ genes in dolphin genome and all these genes were proved to be pseudogenes. Thus, we used these 10 Tas2rs from cow and dog reference genomes to search the Yangtze River dolphin (or baiji, Lipotes vexillifer) genome for the raw members of these genes and further compared them to dolphin assembly. Eventually, we identified 8 Tas $2 r s$ excluding Tas $2 r 38$ and Tas $2 r 62 b$ in baiji genome, so we used the 10 Tas2rs in Jiang et al. 2012 to conduct our experiment. Sour and salt taste receptors are ion channels. To date, several candidate sour taste receptors have been reported, including acid sensing ion channels (ASICs) [32], hyperpolarization activated cyclic nucleotide gated potassium channels (HCNs) [33], potassium channels [34], and polycystic kidney disease 1 L3 and 2 L1 heteromers (PKD1L3+ PKD2L1) [35-37]. Here we chose PKD2L1 to investigate whether cetaceans retained the sour taste modality, because mice lacking the $P k d 2 l 1$ gene have reduced sour taste ability and some people who are sour-ageusic also showed loss of the $P k d 2 l 1$ gene $[38,39]$. Opposite taste responses are observed for saline solutions of different concentrations; low concentrations are perceived as attractive while concentrated solutions are aversive. These opposing responses are reported to be perceived by different receptors and different pathways [14-16]. The epithelial sodium channel $\mathrm{ENaC}$ is involved in attractive sodium sensing and knockout of $\mathrm{ENaC \alpha}$ in mice resulted in a complete loss of salt attraction and salt response $[40,41]$.

Promoted by the discovery of taste receptor genes, the evolutionary history of taste perception under certain ecological and feeding behaviors has been studied in detail in recent decades. For example, Tas1rs, consisting of three members, Tas1r1, Tas1r2 and Tas1r3, are relatively highly conserved in almost all vertebrates [42]. A pseudogenized Tas1r1 has been reported in the giant panda (Ailuropoda melanoleuca) and was suggested to coincide with the loss of the umami taste modality [43,44]. The chicken (Gallus gallus) has lost Tas1r2 and thus may be insensitive to sweet compounds [42], whereas three vampire bats, the hairy-legged vampire bat (Diphylla ecaudata), common vampire bat (Desmodus rotundus), and white-winged vampire bat (Diaemus youngi), have lost both umami and sweet taste modalities [45,46]. Jiang et al. (2012) [31] reported that all three Tas1rs were lost in sea lion (Zalophus californianus) and the common bottlenose dolphin (Tursiops truncatus), which is consistent with their unique feeding behavior of swallowing food whole without chewing. Tas2rs are less conserved than Tas1rs [42]. The number of Tas2rs ranges from three in chicken to 69 in the guinea pig (Cavia porcellus), with an average number of $\sim 30$ in mammals
[47,48], and the similarity of Tas2rs is approximately $30-70 \%$ [28]. By searching the dolphin genome (at $2.59 \times$ coverage), Jiang et al. (2012) [31] demonstrated that dolphins have lost sweet, umami and bitter taste perception; however, they did not investigate the other two taste modalities, sour and salt. Li et al. (2014) [47] investigated Tas2rs gene repertoires in vertebrates, and they demonstrated that dietary toxins are a major selective force shaping the diversity of the Tas $2 r$ repertoire.

To investigate the cetacean taste system and to test hypotheses proposed in previous studies, we designed degenerate PCR primers to amplify all three Tas1rs, ten Tas2rs, Pkd2l1, and three ENaC members (ENaC $\alpha, \beta$ and $\gamma$ ) from cetacean genomes. Our results indicate that almost all cetaceans have lost sour, sweet, umami and most of the bitter taste modality, while the salt taste may be the only modality retained in cetaceans.

\section{Results and discussion}

Loss of sour, sweet, bitter and umami taste modalities in cetaceans

We successfully amplified Tas1r1, Tas1r2, Pkd2l1, 10 bitter taste receptor genes (Tas2r1, Tas2r2, Tas2r3, Tas2r5, Tas2r16, Tas2r38, Tas2r39, Tas2r60, Tas2r62a and Tas2r62b), and three salt taste receptor genes (scnn1a, scnn $1 b$ and scnn $1 g$ ) from major lineages of cetaceans (7-11 toothed whales and 1-2 baleen whales) and from Hippopotamidae (Hippopotamus amphibious) (Figures 1a, b, Additional file 1: Table S1 and Additional file 2: Tables S2S7). These sequences were deposited in GenBank [GenBank: KJ524713-KJ524837]. Multiple ORF-disrupting indels and premature stop codons were identified in sour, sweet, bitter and umami taste receptor genes in all cetaceans. Tas $2 r 16$ was intact in the baleen whale. We mapped these mutations and premature stop codons onto all the amplified gene sequences, except for Tas $2 r 62 a$ and Tas $2 r 62 b$, because useful reference sequences were not available for these two genes (Additional file 3: Figures S1-S11). Furthermore, for Hippopotamidae, Tas1r1, Tas1r2, Tas2r2 and Tas2r3 were found to be intact, but Pkd2l1, Tas2r1 and Tas $2 r 60$ were pseudogenized. Based on the location of the first premature stop codon in the secondary structure of each protein, all these inactivation mutations are predicted to cause protein truncation (Additional file 4: Table S8). Although we have tried multiple primers to amplify Tas1r3, we failed to amplify even one exon eventually. Considering that both Tas1r1 and Tas1r 2 had been identified as pseudogenes, we speculated that the umami and sweet tastes had been lost in the cetaceans. According to sequence alignments of the three salt taste receptor genes, we did not identify any inactivation mutations in salt taste receptor genes in cetaceans or Hippopotamidae. For Tas1r1, Tas1r2, Pkd2l1, and 10 Tas2rs genes, we only 


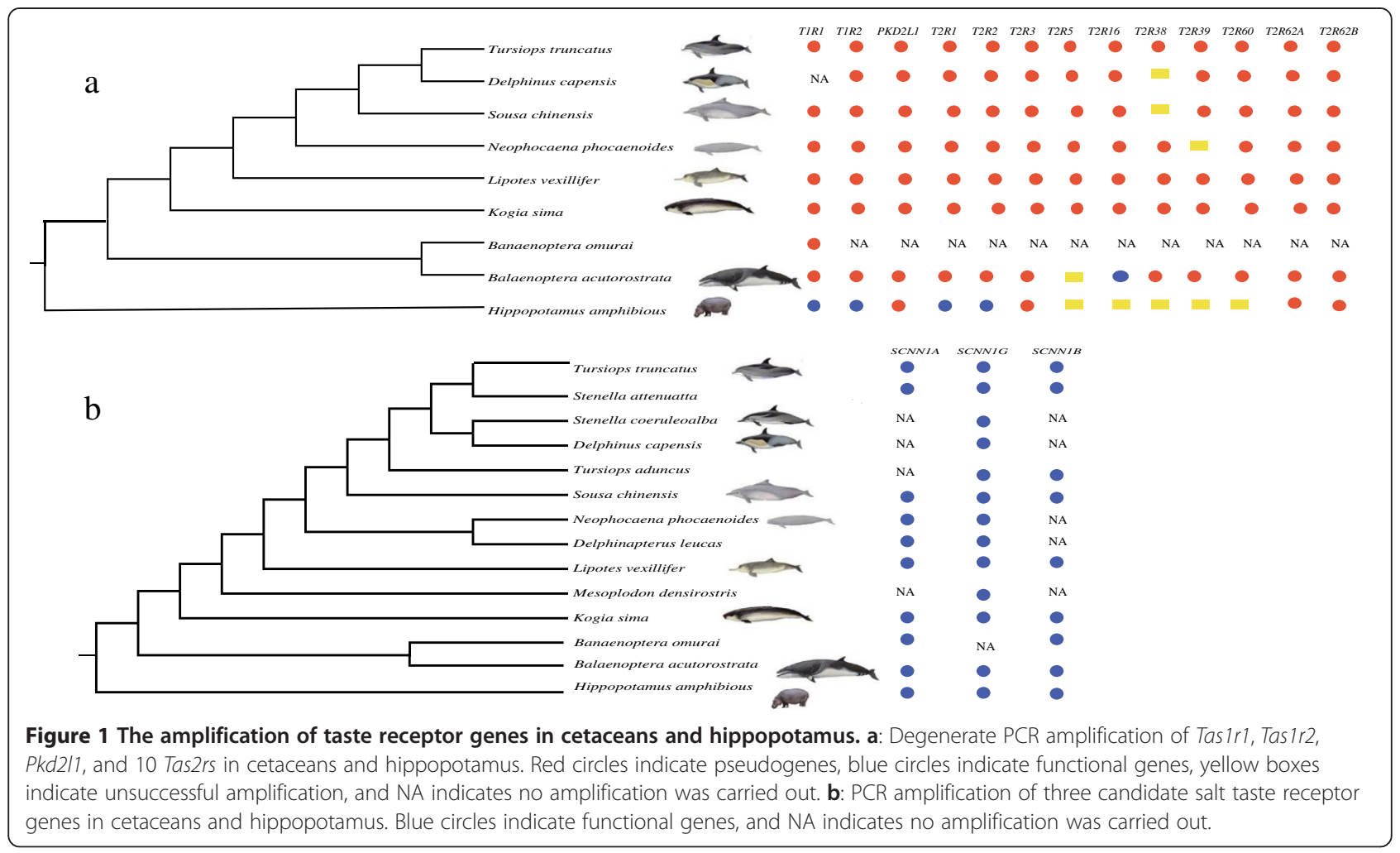

chose 7 cetacean species to represent most major cetacean lineages. Considering that we have identified some shared indels and/or premature stop codons in these genes of some cetacean lineages, it is reasonable to make a conclusion that these genes might have become pseudogenized in cetaceans. However, it is necessary to pay more attention to sensory perception of cetaceans in the future, particularly using high-throughput DNA sequencing techniques and sampling more genes in more species.

Six exons of Tas1r1 and Tas1r2 stretching from nearly the beginning of the $\mathrm{N}$-terminus to the end of the $\mathrm{C}$ terminus were amplified in the major cetacean lineages and Hippopotamidae (Additional file 2: Tables S2-S3). PKD2L1 is composed of an intracellular N-terminal region, a six transmembrane domain and an intracellular C-terminal region [49]. A total of $15 P k d 2 l 1$ exons were amplified in representative cetacean branches and Hippopotamidae (Additional file 2: Table S4). Bitter compounds are perceived by numerous intronless Tas 2 rs [28-30]. Jiang et al. (2012) [31] have identified 10 Tas2rs by searching dolphin's genome, and showed dolphin may have lost bitter taste perception owing to pseudogenization of these 10 Tas $2 r s$. Here we successfully amplified these 10 Tas $2 r$ genes, ranging from 872 to 1,161 bp and used these to explore the evolution of Tas2rs in extant cetaceans and Hippopotamidae (Additional file 1: Table S1).
Based on sequence alignments against cow (Bos taurus) homologues, we identified multiple ORF-disrupting indels and premature stop codons in Tas1r1, Tas1r2, Pkd2l1 and in ten Tas2rs scattered among cetacean branches. We also found ORF-disrupting mutations in Pkd2l1 and in two bitter taste receptor genes (Tas2r3 and Tas2r60) in Hippopotamidae (Additional file 3: Figures S1-S11). All these inactivating mutations were mapped onto the species tree (Additional file 5: Figures S12-S22), and the locations of the first premature stop codons are listed in Additional file 4: Table S8. For Tas1r1, we identified a premature stop codon shared by all cetaceans, a 5 bp deletion shared by all toothed whales and a 17 bp deletion in two baleen whales (Additional file 3: Figure S2). For Tas1r2, a 5 bp deletion was found on the stem Odontoceti (Additional file 3: Figure S3), suggesting that the pseudogenization event had happened in the common ancestor of the Odontoceti. The ability to sense sour-taste substances is important for protecting mammals from ingesting toxic food. For PKD2L1, the sole candidate sour taste receptor, we found two premature stop codons shared by all toothed whales, excluding the Dwarf sperm whale (Kogia sima) and a premature TGA stop codon shared by all cetaceans except for the baiji (Additional file 3: Figure S1). Interestingly, the ninth exon of $P k d 2 l 1$ was lost in the finless porpoise (Neophocaena phocaenoides) (Additional file 3: Figure S1), which was confirmed by an additional eight individuals. 
We amplified 10 Tas2rs, including Tas2r1-3, 5, 16, 38$39,60,62 a$ and Tas2r62b in cetaceans and in five members of them in Hippopotamidae members (Additional file 1: Table S1). Compared with corresponding functional sequences of Tas $2 r 1$, we found a 1 bp deletion in three species of Delphinidae, a premature stop codon (TGA) in all cetaceans except for the Dwarf sperm whale, and another premature stop codon (TGA) in four toothed whales (Additional file 3: Figure S4). In Tas2r2, Tas $2 r 5$ and Tas2r16, we found shared ORF-disrupting mutations and/or premature stop codons in all toothed whales, such as a 1 bp or a 2 bp deletion in Tas $2 r 2$ (Additional file 3: Figure S5), a shared TGA premature stop codon in Tas2r5 (Additional file 3: Figure S7), and a 4 bp deletion in Tas2r16 (Additional file 3: Figure S8), suggesting that the functional loss of these genes happened in the common ancestor of toothed whales. However, we could not exclude the possibility that the pseudogenization event in Tas2r2 might have occurred in the ancestor of all cetaceans, although we failed to amplify the whole Tas2r2 sequence in the common minke whale (Balaenoptera acutorostrata). Most interestingly, the common minke whale still had an intact Tas2r16, but whether it is still functional requires further investigation. Shared inactivating mutations in Tas $2 r 3$, Tas2r38, Tas $2 r 39$ and Tas2r60 were all successfully mapped on the stem cetaceans, although Tas $2 r 38$ was successfully amplified in only five species. A 1 bp deletion in Tas2r3 (Additional file 3: Figure S6), a 2 bp deletion in Tas2r38 (Additional file 3: Figure S9), a 4 bp insertion in Tas2r39 (Additional file 3: Figure S10), and a shared TGA premature stop codon in Tas2r60 (Additional file 3: Figure S11) were identified, suggesting that the functional loss happened in the common ancestor of the cetaceans. For Tas2r62a and Tas2r62b, we could not definitively identify indels because the homologous gene in cow is a pseudogene and in dog only a portion of the gene has been reported and may, therefore, not be functional. However, we are confident that both Tas2r62a and Tas2r62b in cetaceans are pseudogenes because correct translation reveals multiple premature stop codons. For the three pseudogenized Tas2rs of Hippopotamidae, no shared ORF-disrupting mutation was found between cetaceans and Hippopotamidae, suggesting independent pseudogenization events in cetaceans and Hippopotamidae.

\section{Relaxation of selective pressure on taste genes}

To evaluate the selective pressure on these pseudogenized taste receptor genes in cetaceans, the ratios of nonsynonymous to synonymous substitutions $\left(d_{\mathrm{N}} / d_{\mathrm{S}}\right)$ were calculated (Table 1). For Tas1r1-2 and Pkd2l1, based on the assumption that all branches had a single $\omega$ value, purifying selection was seen across the tree for the three genes according to comparison between model A and model B $(\omega=0.2919, p=0 ; \omega=0.20585, p=0 ; \omega=0.28788$, $p=0$; respectively). Further comparison between model A and model $\mathrm{C}$ in which pseudogenized branches had a $\omega_{2}$ while other branches had a $\omega_{1}$ showed that $\omega$ in pseudogenized branches was significantly higher for umami, sweet, and sour taste receptor genes $\left(\omega_{1}=0.25599, \omega_{2}=\right.$ 0.68390 in model C, $p=2.82 \mathrm{E}-12$ in dataset I; $\omega_{1}=$ 0.17096, $\omega_{2}=0.49085$ in model C, $p=7.97 \mathrm{E}-14$ in dataset II; $\omega_{1}=0.24058, \omega_{2}=0.55166$ in model C, $p=1.35 \mathrm{E}-07$ in dataset III), indicating that functional constraint was slightly relaxed in cetaceans for Tas1rland Tas $1 r 2$ and in cetaceans plus Hippopotamidae for Pkd2l1. To further evaluate whether selective pressure was completely removed, we performed comparisons between model $C$ and model $\mathrm{D}$ which had a fixed $\omega_{2}=1$ in pseudogenized branches. This analysis showed that functional constraints on Tas1r1and Tas1r2 were not completely removed in cetaceans nor on $P k d 2 l 1$ in cetaceans plus Hippopotamidae $(p=0.01$ in model $\mathrm{C}$ vs $\mathrm{D}$ of dataset I; $p=9.90 \mathrm{E}-07$ in model C vs D of dataset II; $p=5.45 \mathrm{E}-05$ in model C vs D of dataset III). Finally, model E, which allowed different branches their own $\omega$ was significantly fixed the data than model C $(p=2.33 \mathrm{E}-05$ in model $\mathrm{C}$ vs $\mathrm{E}$ of dataset I; $p=2.41 \mathrm{E}-05$ in model $\mathrm{C}$ vs $\mathrm{E}$ of dataset II; $p=6.78 \mathrm{E}-07$ in model $C$ vs $E$ of dataset III), indicative of variable $\omega$ across the tree for the three genes.

We analyzed seven bitter taste receptor genes, excluding Tas2r38, Tas $2 r 62 a$ and Tas $2 r 62 b$ because the species from which we successfully amplified Tas $2 r 38$ were scarce, and we only retrieved pseudogenes as query sequences for Tas2r62a and Tas2r62b. The analysis process was similar to that for Tas1r1, Tas1r2 and Pkd2l1, and found that the functional constraints were almost completely removed from these seven Tas2rs (Additional file 6: Tables S9-S15).

The shift of habitat from land to water approximately 52.5 Mya and subsequent changes in feeding behavior and habitat might have contributed to the loss of the four tastes in cetaceans. For example, basal cetaceans have several suites of synapomorphies, including reduction of the crushing basins of teeth, which suggested a major change of dental function, and development of the long and narrow postorbital and temporal region of the skull in early cetaceans. Those synapomorphies could affect sense organs and may be related to dietary changes in early cetaceans $[50,51]$. Alongside living in aquatic water environments, cetaceans have evolved unique feeding behaviors including the swallowing of food without chewing in toothed whales and filtering in baleen whales [52,53]. These behaviors further reduced their dependence on taste in the search for food resources. Anatomical evidence also reveals that both toothed and baleen whales have degenerated tongue epithelia containing only few taste buds [54-56]. The tongues of the Pacific whitesided 
Table 1 Likelihood ratio tests of various models on the selective pressures on Tas1r1, Tas1r2, Pkd2/1, and Scnn1g

\begin{tabular}{|c|c|c|c|c|c|c|c|}
\hline & Models & $\omega$ & $-\ln L$ & $\mathrm{np}$ & $\begin{array}{l}\text { Models } \\
\text { compared }\end{array}$ & $2 \Delta(\ln L)$ & $p$-value \\
\hline \multirow[t]{8}{*}{ Dataset I: } & \multicolumn{7}{|l|}{ Tas1r1 } \\
\hline & All branches have one $\omega(A)$ & 0.2919 & 12711.16 & 28 & & & \\
\hline & All branches have one $\omega=1(\mathrm{~B})$ & 1 & 13033.12 & 27 & B vs. A & 643.92 & 0 \\
\hline & \multirow{2}{*}{$\begin{array}{l}\text { The branches with pseudogenized Tas } 1 r 1 \text { has } \omega_{2} \text {, } \\
\text { others have } \omega_{1}(C)\end{array}$} & $\omega_{1}=0.25599$ & \multirow[t]{2}{*}{12686.76} & \multirow[t]{2}{*}{29} & \multirow[t]{2}{*}{ A vs. C } & \multirow[t]{2}{*}{48.81} & \multirow[t]{2}{*}{$2.82 \mathrm{E}-12$} \\
\hline & & $\omega_{2}=0.68390$ & & & & & \\
\hline & \multirow{2}{*}{$\begin{array}{l}\text { The branches with pseudogenized Tas } 1 r 1 \text { has } \omega_{2}=1 \text {, } \\
\text { others have } \omega_{1}(D)\end{array}$} & $\omega_{1}=0.25589$ & \multirow[t]{2}{*}{12690.33} & \multirow[t]{2}{*}{28} & \multirow[t]{2}{*}{ D vs. C } & \multirow[t]{2}{*}{7.15} & \multirow[t]{2}{*}{0.01} \\
\hline & & $\omega_{2}=1.00000$ & & & & & \\
\hline & Each branch has its own $\omega(E)$ & Variable $\omega$ by branch & 12655.22 & 53 & C vs. E & 63.06 & 2.33E-05 \\
\hline \multirow[t]{6}{*}{ Dataset II: } & \multicolumn{7}{|l|}{ Tas1r2 } \\
\hline & All branches have one $\omega(A)$ & 0.20585 & 11866.17 & 24 & & & \\
\hline & All branches have one $\omega=1(\mathrm{~B})$ & 1 & 12287.21 & 23 & B vs. A & 842.08 & 0 \\
\hline & $\begin{array}{l}\text { The branches with pseudogenized Tas } 1 r 2 \text { has } \omega_{2} \text {, } \\
\text { others have } \omega_{1}(C)\end{array}$ & $\omega_{1}=0.17096 \omega_{2}=0.49085$ & 11838.26 & 25 & A vs. C & 55.81 & 7.97E-14 \\
\hline & $\begin{array}{l}\text { The branches with pseudogenized Tas } 1 r 2 \text { has } \omega_{2}=1 \text {, } \\
\text { others have } \omega_{1}(D)\end{array}$ & $\omega_{1}=0.16972 \omega_{2}=1.00000$ & 11850.23 & 24 & D vs. C & 23.95 & 9.90E-07 \\
\hline & Each branch has its own $\omega(E)$ & Variable $\omega$ by branch & 11809.99 & 45 & C vs. E & 56.54 & 2.41E-05 \\
\hline \multirow[t]{7}{*}{ Dataset III: } & \multicolumn{7}{|l|}{$P k d 2 / 1$} \\
\hline & All branches have one $\omega(A)$ & 0.28788 & 8723.86 & 28 & & & \\
\hline & All branches have one $\omega=1(\mathrm{~B})$ & 1 & 8907.34 & 27 & B vs. A & 366.97 & 0 \\
\hline & $\begin{array}{l}\text { The branches with pseudogenized } P k d 2 / 1 \text { has } \omega_{2} \text {, } \\
\text { others have } \omega_{1}(C)\end{array}$ & $\omega_{1}=0.24058 \omega_{2}=0.55166$ & 8709.97 & 29 & A vs. C & 27.79 & 1.35E-07 \\
\hline & \multirow{2}{*}{$\begin{array}{l}\text { The branches with pseudogenized } P k d 2 / 1 \\
\text { has } \omega_{2}=1 \text {, others have } \omega_{1} \text { (D) }\end{array}$} & $\omega_{1}=0.23991$ & \multirow[t]{2}{*}{8718.11} & \multirow[t]{2}{*}{28} & \multirow[t]{2}{*}{ D vs. C } & \multirow[t]{2}{*}{16.29} & \multirow[t]{2}{*}{$5.45 \mathrm{E}-05$} \\
\hline & & $\omega_{2}=1.00000$ & & & & & \\
\hline & Each branch has its own $\omega(E)$ & Variable $\omega$ by branch & 8673.30 & 53 & C vs. E & 73.33 & $6.78 \mathrm{E}-07$ \\
\hline \multirow[t]{9}{*}{ Dataset IV: } & \multicolumn{7}{|l|}{ Scnnig } \\
\hline & \multirow{2}{*}{$\begin{array}{l}\text { All branches in cetaceans have a } \omega_{3} \text {, other branches } \\
\text { have a } \omega_{2} \text {. (F) }\end{array}$} & $\omega_{2}=0.19790$ & \multirow[t]{2}{*}{8999.60} & \multirow[t]{2}{*}{46} & & & \\
\hline & & $\omega_{3}=1.05041$ & & & & & \\
\hline & $\begin{array}{l}\text { M2a-rel: All branches in cetaceans have a } \omega_{31} \\
\text { other branches have a } \omega_{2}, \omega_{2}=\omega_{3} .(G)\end{array}$ & $\omega_{2}=\omega_{3}=0.25665$ & 9036.40 & 45 & F vs $G$ & 73.58 & 0 \\
\hline & \multicolumn{7}{|l|}{ Site model } \\
\hline & M1a (nearly neutral) & $\omega_{0}=0.05745 \omega_{1}=1.00000$ & 9068.93 & 43 & & & \\
\hline & M2a (positive selection) & $\begin{array}{l}\omega_{0}=0.05745 \omega_{1}=1.00000 \\
\omega_{2}=1.00000\end{array}$ & 9068.93 & 45 & M1a VS M2a & 0 & 1 \\
\hline & M8a & $\omega=1.00000$ & 9037.05 & 44 & & & \\
\hline & M8 & $\omega=1.35413$ & 9036.59 & 45 & M8a VS M8 & 0.93 & 0.33 \\
\hline
\end{tabular}

dolphin (Lagenorhynchus obliquidens), bottlenose dolphin, striped dolphin (Stenella coeruleoalba), and baiji have been reported to lack circumvallate papilla, foliate papilla and fungiform papilla [54-56]. Furthermore, most cetaceans live in oceans where high concentrations of sodium might mask other taste modalities. This would further decrease their dependence on taste for seeking out prey, leading to the loss of basic taste modalities.

It is noteworthy that there are many reports detailing the distribution of Tas1rs and Tas2rs in non-oral cavities, including intestinal tract [57-60], respiratory tract [61-63], pancreas [64] and brain [65,66], and in these non-oral cavities these taste receptors can also interact with taste substances but they induce different reactions. There are also other receptors that detect small peptides and amino acids such as metabotropic glutamate receptors (mGluRs) and calcium-sensing receptors (CaSRs) [67-70]. We, therefore, cannot exclude the possibility that cetaceans may retain some umami taste despite Tas1r1 being pseudogenized. It will be interesting to investigate other candidate umami taste receptors to see whether cetaceans have completely lost the umami taste. 


\section{Salt taste is the sole functional taste modality retained in cetaceans}

The sense of salt taste can contribute to the ingestion of $\mathrm{Na}^{+}$and other minerals. It is widely believed that the epithelial sodium channel $(\mathrm{ENaC})$, composed of three homologous $\mathrm{ENaC} \alpha, \beta$ and $\gamma$ subunits, plays a crucial role in the perception of salt taste $[15,71,72]$. Belonging to the $\mathrm{ENaC} /$ degenerin family, $\mathrm{ENaC}$ was proposed to be an $\alpha-\gamma-\beta$ trimer based on the structure of ASIC1 (acid sensing ion channel 1), which is another member of the $\mathrm{ENaC} /$ degenerin family [73]. Each $\mathrm{ENaC}$ subunit consists of an intracellular $\mathrm{N}$ terminal region, an intracellular $\mathrm{C}$ terminal region, and a two-transmembrane domain [72]. Here, we successfully amplified $\mathrm{ENaC} \alpha, \beta$ and $\gamma$ subunits encoded by scnn1a, scnn $1 b$ and scnn $1 g$, respectively, in representative toothed and baleen whales and in Hippopotamidae (Additional file 1: Table S1 and Additional file 2: Tables S5-S7).

No inactivating mutation was identified in any of these three genes. Furthermore, we have identified multiple conserved residues in cetaceans that are essential for channel function. These conserved residues reside in motifs that include the conserved proline-rich motifs containing PPPXYXXL residues in the C-terminus, HG residues in the N-terminus, FPXXTXC in post-M1 (first transmembrane domain), completely conserved residues in the second transmembrane domain (M2), and conserved Cys-rich domains in the extracellular loop [74]. All of these conserved motifs are essential for channel function, for example post-M2 and M2 constitute the outer pore entry and selectivity filter [74], conserved HG in the Nterminus plays an important role in gating [75], Cys-rich domains are vital for tertiary structure of the extracellular loop [76], and conserved proline-rich motifs in the $C$ terminus take part in channel ubiquitination, endocytosis, and degradation of the $\mathrm{ENaC}[77,78]$. Based on sequence alignments, Scnn1a, Scnn1b and Scnn1g possessed all these conserved amino acids, except for a conserved HG in the N-terminus of Scnnla, a conserved FPXXTXC in post-M1, and two important residues in the Cys-rich domains of Scnn1b; however these omissions are likely to be because of our incomplete gene amplification. Interestingly, we identified a variable residue, $\gamma$ V591I, in the completely conserved M2 motif in the baiji. Among residues with $80 \%$ or greater conservation in $\mathrm{M} 2$, we identified a $\gamma$ V590I variation in toothed whales, a $\gamma$ V593I variation in all toothed whales except for the beaked whale (Mesoplodon densirostris), and a $\alpha \mathrm{M} 596 \mathrm{~V}$ variation in cetaceans (Figure 2). These substitutions probably affect the formation of the channel pore based on their distribution in pre-M2 and M2, which are known to participate in the formation of the channel pore. Even though we could not

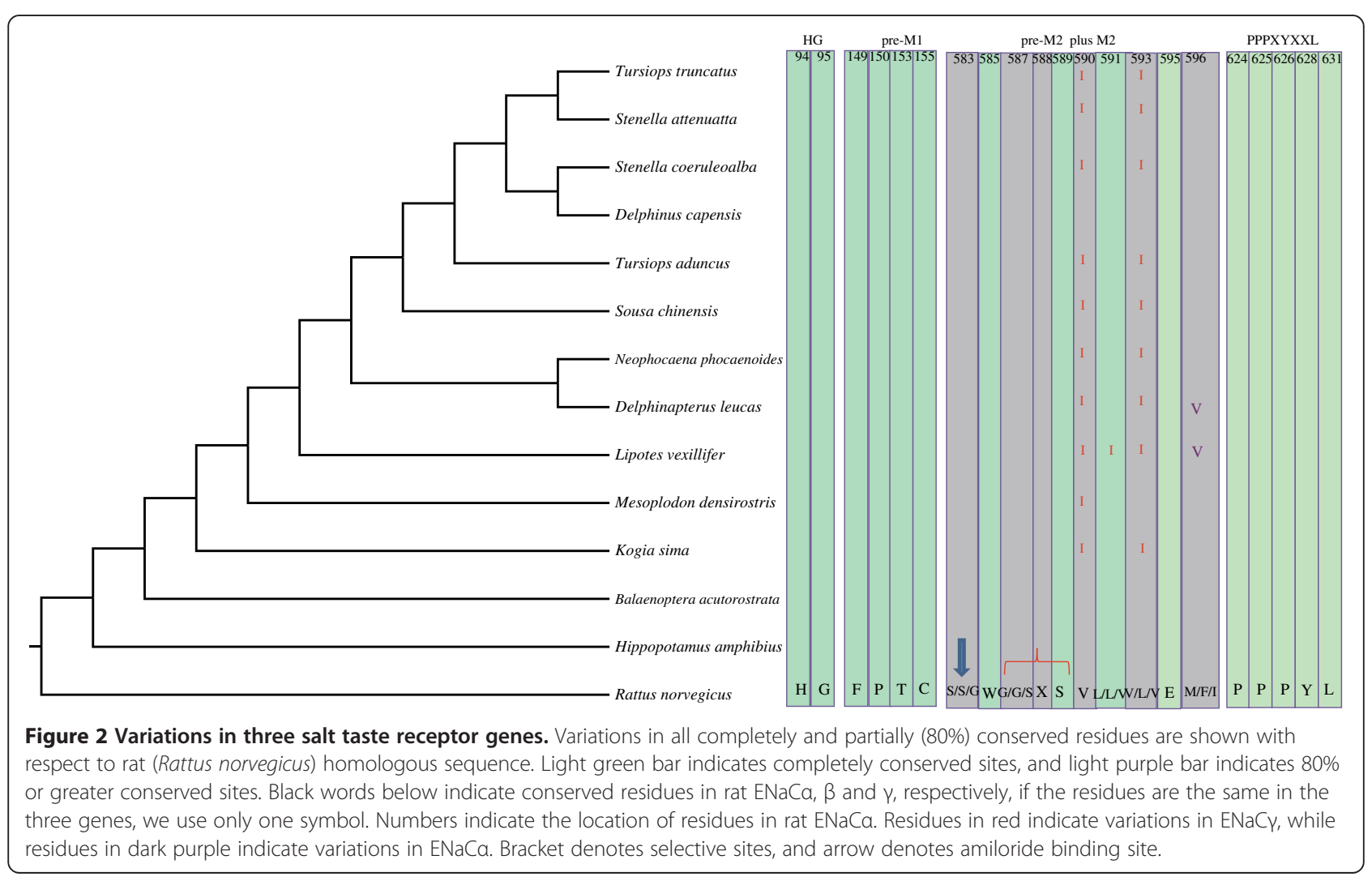


identify all conserved sequences owing to incomplete amplification, the above analyses strongly suggested that the salt taste genes were intact.

We used site models (m1a vs m2a; m8 vs m8a), and branch site model to test whether salt taste receptor genes were under positive selection, and Clade model $\mathrm{C}$ (compared with $\mathrm{m} 2 \mathrm{a}_{-}$rel, a null model for Clade model C) was used to identify divergent selection acting on different clades $[79,80]$. For scnn1g, Clade model C marked all cetaceans as foreground branches, with $\omega_{3}=1.05041$ for the foreground branch and $\omega_{2}=0.19790$ for the background branch (F vs G of dataset IV in Table 1), which is significantly better than m2a_rel $(p=0)$. Our clade model showed evidence of significant divergent selection, and the $\omega$ in cetacean was greater than one, suggesting positive selection of this gene in cetacean clade. M8 in the site model also identified some positively selected sites, although the model was not significantly better than the null model $(p=0.33)$ and the $p$-values of the sites were less than 95\% (Dataset IV in Table 1). Using the latest model FUBAR [81], we also identified four pervasive diversifying selection sites at posterior probability $\geq 0.8$ (data not shown). Because amino acid substitution affects proteins by altering their physicochemical properties and structure, we employed a complementary protein-level approach implemented in TreeSAAP [82]. Our TreeSAAP analysis identified four significant physicochemical changes owing to amino acid residues changes in $\mathrm{ENaC} \gamma$ : equilibrium constant (ionization of $\mathrm{COOH}$ ), isoelectric point, power to be at the Cterminal and tendency to form alpha-helix (Additional file 7: Table S16). Selective pressure analysis of $\mathrm{ENaC \alpha}$ and $\mathrm{ENaC} \beta$ failed to identify positive signatures, suggesting that scnn1a and scnn $1 b$ are still under strong purifying selection (data not shown). Our TreeSAAP analysis identified eleven and five significant physicochemical amino acid changes in $\mathrm{ENaC} \alpha$ and $\beta$, respectively (Additional file 7: Table S16). These significant changes may contribute to cetaceans' adaptation by increasing $\mathrm{ENaC}$ activities.

$\mathrm{ENaC}$ is widely distributed in tissues associated with $\mathrm{Na}^{+}$transport, including kidney, distal colon, lung, sweat ducts, salivary ducts and skin, and plays vital roles in these tissues [41,72]. In lung, the main function of $\mathrm{ENaC}$ is not only in ion and water homeostasis, but also in maintaining the appropriate level of hydration of the fluid layer [83]. ENaC $\alpha$ knockout mice die within a few days after birth because they fail to clear fetal lung liquid [84]. In the kidney and distal colon, $\mathrm{ENaC}$ is vital for the homeostasis of blood $\mathrm{K}^{+}$and $\mathrm{Na}^{+}$levels, especially in the kidney where channels have an important role in overall $\mathrm{Na}^{+}$balance [83]. Mutations in the conserved HG motifs cause a renal salt-wasting syndrome called pseudohypoaldosteronism type 1 (PHA-1) [85], and mutations in the conserved PPPXY motif in $\beta$ - and $\gamma$-ENaC subunits are associated with Liddle's syndrome, a form of monogenic hypertension [86,87]. Cetaceans living in the hyperisotonic marine environment have to overcome the problems caused by high concentrations of sodium in the water. The osmotic pressure of urine is higher than the vascular osmotic pressure in cetaceans [88-92]. Thus, the importance of $\mathrm{ENaC}$ in ion and water homeostasis and in maintaining the appropriate level of hydration of the fluid layer may have provided selective pressure to preserve salt taste receptor function in cetaceans. This is probably related to their distribution in the kidney especially in cortical collecting tubes and to their function in $\mathrm{Na}^{+}$reabsorption [83]. Taking into consideration the degenerated tongue epithelia in cetaceans and the importance of $\mathrm{ENaC}$ in the kidney and other organs, we propose that the intact of $\mathrm{ENaC}$ may be owed to its function in kidneys and other organs. Whether cetaceans can taste salt is still unknown; the answer to this question awaits further investigation.

\section{Conclusions}

Receptor genes for the five specific tastes were investigated among the major cetaceans and the five basic taste modalities were assessed in marine mammals. Cetaceans appear to have lost four basic taste modalities including sour, sweet, umami, and the majority of the bitter taste sensation. However, as for umami taste, there are also other receptors that detect small peptides and amino acids, making it necessary to detect other candidate genes of umami to further reveal the evolution pattern of cetacean umami receptors. The integrity of salt receptor genes in all cetaceans studied here, may be owed to their function in $\mathrm{Na}^{+}$reabsorption, which is key to osmoregulation during aquatic adaptation.

\section{Methods}

\section{Polymerase chain reaction and DNA sequencing}

Genomic DNA was extracted from muscle and/or blood samples from representative cetaceans including toothed and baleen whales, and the hippo (Hippopotamus amphibious) using a standard phenollchloroform protocol [93]. Cetacean samples were collected from stranded or incidentally captured/killed animals in coastal China Seas by our lab members; therefore, ethical approval has not been requested. When the aquatic mammals were reported to be stranded or incidental captured/killed, we contacted local Oceanic and Fisheries Bureaus which perform conservation and management of aquatic animals on behalf of Chinese government. Once we got their permissions, we went to the sites of stranding or incidental catching to collect animal tissue samples for research purpose. The hippo sample was a piece of muscle sampled from an died individual, which was provided to us by Chengdu Zoo, Sichuan Province, China for the present study, and we have permission from this 
institution to conduct our experiments on this sample. Voucher specimens were preserved at Nanjing Normal University. Based on alignments of homologous taste receptor genes for the five taste modalities between the common bottlenose dolphin (http://asia.ensembl.org/ Tursiops_truncatus/Info/Index) and cattle (http://asia. ensembl.org/Bos_taurus/Info/Index), a series of degenerate primers were designed (Additional file 8: Table S17). PCR reactions $(30 \mu \mathrm{l})$ contained $0.8 \mu \mathrm{l}$ genomic DNA, 1 unit of Taq polymerase (Takara), $0.2 \mu \mathrm{mol}$ of each primer, $3 \mu \mathrm{l}$ of $10 \times$ PCR buffer, $0.2 \mu \mathrm{mol}$ of dNTP and $2.5 \mu \mathrm{mol}$ of $\mathrm{MgCl}_{2}$. Cycling parameters were as follows: denaturation at $95^{\circ} \mathrm{C}$ for $5 \mathrm{~min}$, then 35 cycles of $95^{\circ} \mathrm{C}$ for $30 \mathrm{~s}, 55-58^{\circ} \mathrm{C}$ for $40 \mathrm{~s}, 72^{\circ} \mathrm{C}$ for $40 \mathrm{~s}$, and finally an elongation at $72^{\circ} \mathrm{C}$ for $10 \mathrm{~min}$. The amplified PCR products were separated by agarose gel electrophoresis and gel-purified products were cloned into pMD18-T (Takara). PCR products were sequenced in both directions using an ABI PRISM 3730 DNA Sequencer. Three to five clones for each gene or pseudogene were obtained to confirm its sequence. Other sequences used in analyses were downloaded from the Ensembl Genome database (http://www. ensembl.org) and GenBank (http://www.ncbi.nlm.nih.gov) with accession numbers listed in Additional file 9: Table S18. The secondary structures of proteins were estimated using TMHMM (http://www.cbs.dtu.dk/services/TMHMM/).

\section{Phylogenetic reconstruction}

To access sequence variability among different species, we used CLUSTAL W [94] in MEGA5 [95] to conduct sequence alignments. To analyze selective pressure, CODEML in PAML v4.4 [79] was used, and we incorporated the widely accepted phylogenetic trees of cetaceans [2,96-98]. For genes with intact open reading frames, nucleotide sequence alignments were conducted based on protein sequence alignment, while for pseudogenes we selected closely related functional sequences as queries to ascertain indels and premature stop codons. In addition, we used the TreeSAAP 3.2 software package [82] to detect significant physicochemical amino acid changes among residues in three $\mathrm{ENaC}$ members. The software program TreeSAAP measures the selective influences on 31 structural and biochemical amino acid properties during cladogenesis, and performs goodness-of-fit and categorical statistical tests [82]. Within TreeSAAP, magnitudes of non-synonymous changes are classified into eight categories according to the change in specific physicochemical properties, in which 1-3 are conservative while 6-8 are radical. After running, a z-score was generated for each category, with a positive $\mathrm{z}$-score meaning that a given region is under positive selection influence. Here, we only considered amino acid properties with significant positive z-scores in categories $6-8$ to be under positive selection, and a sliding window of 15 was performed.

\section{Availability of supporting data section}

The data sets supporting the results of this article are available in the Dryad repository, http://dx.doi.org/ 10.5061/dryad.7qp63 [99]. This repository contains all of the datasets from Table 1.

\section{Additional files}

\begin{abstract}
Additional file 1: Table S1. Degenerate PCR amplification of five tasterelated genes among representative cetaceans and hippopotamus. Note: tick represents successfully amplified.
\end{abstract}

Additional file 2: Tables S2-S7. Statistics for amplified exons from each taste receptor gene for each species. Note: tick represents successfully amplified.

Additional file 3: Figures S1-S11. Indels and premature stop codons in Pkdl21, Tas1r1, Tas1r2, Tas2r1-3, Tas2r5, Tas2r16, Tas2r38-39, and Tas2r60. Indels are highlighted in red, while premature stop codons are indicated in green.

Additional file 4: Table S8. The location of the first premature stop codon in each pseudogenized taste receptor gene. $\mathrm{N}$ represents the $\mathrm{N}$-terminus, FEL represents the First extracellular loop, SEL represents Second extracellular loop, TEL represents the Third extracellular loop, FIL represents the Fourth intracellular loop, TM represents transmembrane domain, SIL represents Second intracellular loop, and NA represents non-amplification in our analysis.

Additional file 5: Figures S12-S22. Indels and premature stop codons mapped on the species tree for pseudogenized taste receptor genes. A list of phylogenetic trees of the taste receptor genes analyzed in the present study with all indels and premature stop codons mapped in order. All indels are characterized with bars, with each color representing a different indel and the same color representing the same indel across the tree. Premature stop codons are characterized with ellipses; we did not differentiate premature stop codons and all have the same color.

Additional file 6: Tables S9-S15. Likelihood ratio tests of various models on the selective pressures on seven bitter taste receptor genes.

Additional file 7: Table S16. Physicochemical properties under positive destabilizing selection in $\mathrm{ENaCa}, \beta, \gamma$.

Additional file 8: Table S17. PCR primers for each taste receptor gene. Additional file 9: Table S18. Accession numbers for species used in PAML analysis.

\section{Competing interests}

The authors declare that they have no competing interests.

\section{Authors' contributions}

GY, XZ and KZ designed the study. KZ and DS carried out the experiments. $K Z$ and $X Z$ performed the data analyses, and prepared the draft of the manuscript. GY, SX, WR, and KZ helped to improve the manuscript. All authors read and approved the final manuscript.

\section{Acknowledgements}

This work was supported by the National Science Fund for Distinguished Young Scholars (grant number 31325025) to GY, the National Natural Science Foundation of China (grant number 31172069 to GY and grant number 31370401 to WHR), the Priority Academic Program Development of Jiangsu Higher Education Institutions to GY and SXX, and the Specialized Research Fund for the Doctoral Program of Higher Education to GY (grant number 20113207130001). Authors wish to thank Mr. Xinrong Xu and Dr. Bingyao Chen for collecting the samples for many years.

\section{Author details}

${ }^{1}$ Jiangsu Key Laboratory for Biodiversity and Biotechnology, College of Life Sciences, Nanjing Normal University, Nanjing 210023, China. ${ }^{2}$ Division of Genetics, Department of Medicine, Brigham and Women's Hospital, Harvard Medical School, Boston, MA 02115, USA. 
Received: 5 March 2014 Accepted: 2 October 2014

Published online: 12 October 2014

\section{References}

1. Gatesy J, Geisler JH, Chang J, Buell C, Berta A, Meredith RW, Springer MS, McGowen MR: A phylogenetic blueprint for a modern whale. Mol Phylogenet Evol 2013, 66:479-506.

2. Zhou X, Xu S, Yang Y, Zhou K, Yang G: Phylogenomic analyses and improved resolution of Cetartiodactyla. Mol Phylogenet Evol 2011, 61:255-264.

3. Fordyce RE: Origins and evolution of Antarctic marine mammals. Geol SoC London Spec Publ 1989, 47:269-281.

4. Thewissen J, Cooper LN, George JC, Bajpai S: From land to water: the origin of whales, dolphins, and porpoises. Evo Edu Outreach 2009, 2:272-288.

5. Uhen MD: The origin (s) of whales. Annu Rev Earth PI Sc 2010, 38:189-219

6. Liu Y, Cotton JA, Shen B, Han X, Rossiter SJ, Zhang S: Convergent sequence evolution between echolocating bats and dolphins. Curr Biol 2010, 20:R53-R54.

7. Liu Y, Rossiter SJ, Han X, Cotton JA, Zhang S: Cetaceans on a molecular fast track to ultrasonic hearing. Curr Biol 2010, 20:1834-1839.

8. Davies K, Cotton JA, Kirwan JD, Teeling EC, Rossiter SJ: Parallel signatures of sequence evolution among hearing genes in echolocating mammals: an emerging model of genetic convergence. Heredity 2012, 108:480-489.

9. Kishida T, Kubota S, Shirayama Y, Fukami H: The olfactory receptor gene repertoires in secondary-adapted marine vertebrates: evidence for reduction of the functional proportions in cetaceans. Biol Lett 2007, 3:428-430.

10. McGowen MR, Clark C, Gatesy J: The vestigial olfactory receptor subgenome of odontocete whales: phylogenetic congruence between gene-tree reconciliation and supermatrix methods. Syst Biol 2008, 57:574-590.

11. Hayden S, Bekaert M, Crider TA, Mariani S, Murphy WJ, Teeling EC: Ecological adaptation determines functional mammalian olfactory subgenomes. Genome Res 2010, 20:1-9.

12. Zhou X, Sun F, Xu S, Fan G, Zhu K, Liu X, Chen Y, Shi C, Yang Y, Huang Z, Chen J, Hou H, Guo X, Chen W, Chen Y, Wang X, Lv T, Yang D, Zhou J, Huang B, Wang Z, Zhao W, Tian R, Xiong Z, Xu J, Liang X, Chen B, Liu W Wang J, Pan S, et al: Baiji genomes reveal low genetic variability and new insights into secondary aquatic adaptations. Nat Commun 2013, 4:2708.

13. Kinnamon SC, Cummings TA: Chemosensory Transduction Mechanisms in Taste. Annu Rev Physiol 1992, 54:715-731.

14. Lindemann B: Taste reception. Physiol Rev 1996, 76:719-766.

15. Heck GL, Mierson S, DeSimone JA: Salt taste transduction occurs through an amiloride-sensitive sodium transport pathway. Science 1984, 223:403-405.

16. Hettinger TP, Frank ME: Specificity of amiloride inhibition of hamster taste responses. Brain Res 1990, 513:24-34.

17. Yoshida R, Horio N, Murata Y, Yasumatsu K, Shigemura N, Ninomiya Y: NaCl responsive taste cells in the mouse fungiform taste buds. Neuroscience 2009, 159:795-803.

18. Eylam $\mathrm{S}$, Spector $\mathrm{AC}$ : Taste discrimination between $\mathrm{NaCl}$ and $\mathrm{KCl}$ is disrupted by amiloride in inbred mice with amiloride-insensitive chorda tympani nerves. Am J Physiol Regul Integr Comp Physiol 2005, 288:R1361-R1368.

19. Garcia J, Hankins WG: The evolution of bitter and the acquisition of toxiphobia. Olfaction Taste 1975, 5:39-45.

20. Glendinning JI: Is the bitter rejection response always adaptive? Physiol Behav 1994, 56:1217-1227.

21. Ganchrow JR, Steiner JE, Daher M: Neonatal facial expressions in response to different qualities and intensities of gustatory stimuli. Infant Behav Dev 1983, 6:473-484.

22. Bachmanov AA, Beauchamp GK: Taste receptor genes. Annu Rev Nutr 2006, 27:389-414.

23. Bachmanov AA, Li X, Reed DR, Ohmen JD, Li S, Chen Z, Tordoff MG, de Jong PJ, WU C, West DB: Positional cloning of the mouse saccharin preference (Sac) locus. Chem Senses 2001, 26:925-933.

24. Max M, Shanker YG, Huang L, Rong M, Liu Z, Campagne F, Weinstein H, Damak S, Margolskee RF: Tas 1r3, encoding a new candidate taste receptor, is allelic to the sweet responsiveness locus Sac. Nat Genet 2001, 28:58-63.

25. Montmayeur J, Liberles SD, Matsunami H, Buck LB: A candidate taste receptor gene near a sweet taste locus. Nat Neurosci 2001, 4:492-498.

26. Nelson G, Hoon MA, Chandrashekar J, Zhang Y, Ryba NJ, Zuker CS: Mammalian sweet taste receptors. Cell 2001, 106:381-390.

27. Nelson G, Chandrashekar J, Hoon MA, Feng L, Zhao G, Ryba NJ, Zuker CS: An amino-acid taste receptor. Nature 2002, 416:199-202.
28. Adler E, Hoon MA, Mueller KL, Chandrashekar J, Ryba NJ, Zuker CS: A novel family of mammalian taste receptors. Cell 2000, 100:693-702.

29. Chandrashekar J, Mueller KL, Hoon MA, Adler E, Feng L, Guo W, Zuker CS, Ryba NJ: T2Rs function as bitter taste receptors. Cell 2000, 100:703-711.

30. Matsunami $\mathrm{H}$, Montmayeur J, Buck LB: A family of candidate taste receptors in human and mouse. Nature 2000, 404:601-604.

31. Jiang P, Josue J, Li X, Glaser D, Li W, Brand JG, Margolskee RF, Reed DR, Beauchamp GK: Major taste loss in carnivorous mammals. Proc Natl Acad Sci USA 2012, 109:4956-4961.

32. Ugawa S, Minami Y, Guo W, Saishin Y, Takatsuji K, Yamamoto T, Tohyama M, Shimada S: Receptor that leaves a sour taste in the mouth. Nature 1998, 395:555-556.

33. Stevens DR, Seifert R, Bufe B, Müller F, Kremmer E, Gauss R, Meyerhof W, Kaupp UB, Lindemann B: Hyperpolarization-activated channels HCN1 and HCN4 mediate responses to sour stimuli. Nature 2001, 413:631-635.

34. Richter TA, Dvoryanchikov GA, Chaudhari N, Roper SD: Acid-Sensitive TwoPore Domain Potassium ( $\mathrm{K} \sim 2 \mathrm{P})$ Channels in Mouse Taste Buds. J Neurophysiol 2004, 92:1928.

35. LopezJimenez ND, Cavenagh MM, Sainz E, Cruz Ithier MA, Battey JF, Sullivan SL: Two members of the TRPP family of ion channels, Pkd113 and Pkd211, are co-expressed in a subset of taste receptor cells. J Neurochem 2006, 98:68-77.

36. Ishimaru $\mathrm{Y}$, Inada $\mathrm{H}$, Kubota $\mathrm{M}$, Zhuang $\mathrm{H}$, Tominaga $\mathrm{M}$, Matsunami $\mathrm{H}$ : Transient receptor potential family members PKD1L3 and PKD2L1 form a candidate sour taste receptor. Proc Natl Acad Sci USA 2006, 103:12569-12574.

37. Huang AL, Chen X, Hoon MA, Chandrashekar J, Guo W, Tränkner D, Ryba NJ, Zuker CS: The cells and logic for mammalian sour taste detection. Nature 2006, 442:934-938.

38. Horio N, Yoshida R, Yasumatsu K, Yanagawa Y, Ishimaru Y, Matsunami H, Ninomiya Y: Sour taste responses in mice lacking PKD channels. PLoS One 2011, 6:e20007.

39. Huque T, Cowart BJ, Dankulich-Nagrudny L, Pribitkin EA, Bayley DL, Spielman Al, Feldman RS, Mackler SA, Brand JG: Sour ageusia in two individuals implicates ion channels of the ASIC and PKD families in human sour taste perception at the anterior tongue. PLoS One 2009, 4:e7347.

40. Chandrashekar J, Kuhn C, Oka Y, Yarmolinsky DA, Hummler E, Ryba NJ, Zuker CS: The cells and peripheral representation of sodium taste in mice. Nature 2010, 464:297-301.

41. Hummler E, Beermann F: Scnn1 sodium channel gene family in genetically engineered mice. J Am Soc Nephrol 2000, 11(suppl 2):S129-S134.

42. Shi P, Zhang J: Contrasting modes of evolution between vertebrate sweet/umami receptor genes and bitter receptor genes. Mol Biol Evol 2006, 23:292-300

43. Li R, Fan W, Tian G, Zhu H, He L, Cai J, Huang Q, Cai Q, Li B, Bai Y, Zhang Z, Zhang Y, Wang W, Li J, Wei F, Li H, Jian M, Li J, Zhang Z, Nielsen R, Li D, Gu W, Yang Z, Xuan Z, Ryder OA, Leung FC, Zhou Y, Cao J, Sun X, Fu Y, et al: The sequence and de novo assembly of the giant panda genome. Nature 2009, 463:311-317.

44. Zhao H, Yang J, Xu H, Zhang J: Pseudogenization of the umami taste receptor gene Tas1 11 in the giant panda coincided with its dietary switch to bamboo. Mol Biol Evol 2010, 27:2669-2673.

45. Zhao H, Zhou Y, Pinto CM, Charles-Dominique P, Galindo-González J, Zhang $\mathrm{S}$, Zhang J: Evolution of the sweet taste receptor gene Tas $1 \mathrm{r} 2$ in bats. Mol Biol Evol 2010, 27:2642-2650.

46. Zhao $H, X u D$, Zhang S, Zhang J: Genomic and genetic evidence for the loss of umami taste in bats. Genome Biol Evol 2012, 4:73-79.

47. Li D, Zhang J: Diet shapes the evolution of the vertebrate bitter taste receptor gene repertoire. Mol Biol Evol 2014, 31:303-309.

48. Meyerhof W: Elucidation of mammalian bitter taste. Rev Physiol Biochem Pharmacol 2005, 154:37-72.

49. González-Perrett S, Kim K, Ibarra C, Damiano AE, Zotta E, Batelli M, Harris PC, Reisin IL, Arnaout MA, Cantiello HF: Polycystin-2, the protein mutated in autosomal dominant polycystic kidney disease (ADPKD), is a $\mathrm{Ca2}^{+}$-permeable nonselective cation channel. Proc Natl Aca Sci USA 2001, 98:1182-1187.

50. Nummela S, Hussain ST, Thewissen J: Cranial anatomy of Pakicetidae (Cetacea, Mammalia). J Vertebr Paleontol 2006, 26:746-759.

51. O'Leary MA, Uhen MD: The time of origin of whales and the role of behavioral changes in the terrestrial-aquatic transition. Paleobiology 1999, 25:534-556.

52. Miller D: Seals and Sea Lions. Stillwater: Voyageur Press; 1998. 
53. Werth AJ: Adaptations of the cetacean hyolingual apparatus for aquatic feeding and thermoregulation. Anat Rec 2007, 290:546-568.

54. Yoshimura K, Shindoh J, Kobayashi K: Scanning electron microscopy study of the tongue and lingual papillae of the California sea lion (Zalophus californianus californianus). Anat Rec 2002, 267:146-153.

55. Yoshimura K, Kobayashi K: A comparative morphological study on the tongue and the lingual papillae of some marine mammals-Particularly of four species of odontoceti and zalophus. Shigaku= Odontology 1997, 85:385-407

56. Li Y: The tongue of Baiji, Lipotes vexillifer. Acta Zool Sin 1983, 29:35-41 (In Chinese with English abstract)

57. Rozengurt E: Taste receptors in the gastrointestinal tract. I. Bitter taste receptors and a-gustducin in the mammalian gut. Am J Physiol-Gastr L 2006, 291:G171-G177.

58. Bezençon C, le Coutre J, Damak S: Taste-signaling proteins are coexpressed in solitary intestinal epithelial cells. Chem Senses 2007, 32:41-49.

59. Margolskee RF, Dyer J, Kokrashvili Z, Salmon KS, llegems E, Daly K, Maillet EL, Ninomiya Y, Mosinger B, Shirazi-Beechey SP: T1R3 and gustducin in gut sense sugars to regulate expression of $\mathrm{Na}^{+}$-glucose cotransporter 1 . Proc Natl Acad Sci USA 2007, 104:15075-15080.

60. Rozengurt E, Sternini C: Taste receptor signaling in the mammalian gut. Curr Opin Pharmacol 2007, 7:557-562.

61. Finger TE, Böttger B, Hansen A, Anderson KT, Alimohammadi H, Silver WL: Solitary chemoreceptor cells in the nasal cavity serve as sentinels of respiration. Proc Natl Acad Sci USA 2003, 100:8981-8986.

62. Shah AS, Ben-Shahar Y, Moninger TO, Kline JN, Welsh MJ: Motile cilia of human airway epithelia are chemosensory. Science 2009, 325:1131-1134.

63. Deshpande DA, Wang WC, Mcllmoyle EL, Robinett KS, Schillinger RM, An SS, Sham JS, Liggett SB: Bitter taste receptors on airway smooth muscle bronchodilate by localized calcium signaling and reverse obstruction. Nat Med 2010, 16:1299-1304

64. Oya M, Suzuki $H$, Watanabe $Y$, Sato $M$, Tsuboi T: Amino acid taste receptor regulates insulin secretion in pancreatic $\beta$-cell line MIN6 cells. Genes Cells 2011, 16:608-616.

65. Ren X, Zhou L, Terwilliger R, Newton SS, De Araujo IE: Sweet taste signaling functions as a hypothalamic glucose sensor. Front Integr Neurosci 2009, 3:12.

66. Singh N, Vrontakis M, Parkinson F, Chelikani P: Functional bitter taste receptors are expressed in brain cells. Biochem Bioph Res Co 2011, 406:146-151.

67. Chaudhari N, Landin AM, Roper SD: A metabotropic glutamate receptor variant functions as a taste receptor. Nat Neurosci 2000, 3:113-119.

68. San Gabriel A, Uneyama H, Yoshie S, Torii K: Cloning and characterization of a novel mGluR1 variant from vallate papillae that functions as a receptor for L-glutamate stimuli. Chem Senses 2005, 30(suppl 1):i25-i26.

69. Toyono T, Seta Y, Kataoka S, Kawano S, Shigemoto R, Toyoshima K: Expression of metabotropic glutamate receptor group I in rat gustatory papillae. Cell Tissue Res 2003, 313:29-35.

70. Conigrave AD, Brown EM: Taste Receptors in the Gastrointestinal Tract II. I-Amino acid sensing by calcium-sensing receptors: implications for $\mathrm{Gl}$ physiology. Am J Physiol-Gastr L 2006, 291:G753-G761.

71. Brand JG, Teeter JH, Silver WL: Inhibition by amiloride of chorda tympani responses evoked by monovalent salts. Brain Res 1985, 334:207-214.

72. Canessa CM, Schild L, Buell G, Thorens B, Gautschi I, Horisberger J, Rossier BC: Amiloride-sensitive epithelial $\mathrm{Na}^{+}$channel is made of three homologous subunits. Nature 1994, 367:463-467.

73. Collier DM, Snyder PM: Extracellular chloride regulates the epithelial sodium channel. J Biol Chem 2009, 284:29320-29325.

74. Kellenberger S, Schild L: Epithelial sodium channel/degenerin family of ion channels: a variety of functions for a shared structure. Physio/ Rev 2002, 82:735-767.

75. Adams CM, Snyder PM, Welsh MJ: Interactions between subunits of the human epithelial sodium channel. J Biol Chem 1997, 272:27295-27300

76. Firsov D, Robert-Nicoud M, Gruender S, Schild L, Rossier BC: Mutational analysis of cysteine-rich domains of the epithelium sodium channel (ENaC). Identification of cysteines essential for channel expression at the cell surface. J Biol Chem 1999, 274:2743-2749.

77. Staub O, Dho S, Henry P, Correa J, Ishikawa T, McGlade J, Rotin D: WW domains of Nedd4 bind to the proline-rich PY motifs in the epithelial $\mathrm{Na}^{+}$channel deleted in Liddle's syndrome. EMBO J 1996, 15:2371.

78. Abriel H, Loffing J, Rebhun JF, Pratt JH, Schild L, Horisberger J, Rotin D, Staub O: Defective regulation of the epithelial $\mathrm{Na}^{+}$channel by Nedd4 in Liddle's syndrome. J Clin Invest 1999, 103:667-673.
79. Yang Z: PAML 4: phylogenetic analysis by maximum likelihood. $\mathrm{Mol}$ Biol Evol 2007, 24:1586-1591.

80. Weadick CJ, Chang BS: An improved likelihood ratio test for detecting site-specific functional divergence among clades of protein-coding genes. Mol Biol Evol 2012, 29:1297-1300.

81. Murrell B, Moola S, Mabona A, Weighill T, Sheward D, Pond SLK, Scheffler K: FUBAR: a fast, unconstrained bayesian approximation for inferring selection. Mol Biol Evol 2013, 30:1196-1205.

82. Woolley S, Johnson J, Smith MJ, Crandall KA, McClellan DA: TreeSAAP: selection on amino acid properties using phylogenetic trees. Bioinformatics 2003, 19:671-672.

83. Garty H, Palmer LG: Epithelial sodium channels: function, structure, and regulation. Physiol Rev 1997, 77:359-396.

84. Hummler E, Barker P, Gatzy J, Beermann F, Verdumo C, Schmidt A, Boucher $\mathrm{R}$, Rossier $\mathrm{BC}$ : Early death due to defective neonatal lung liquid clearance in aENaC-deficient mice. Nat Genet 1996, 12:325-328.

85. Chang SS, Grunder S, Hanukoglu A, Rösler A, Mathew PM, Hanukoglu I, Schild L, Lu Y, Shimkets RA, Nelson-Williams C: Mutations in subunits of the epithelial sodium channel cause salt wasting with hyperkalaemic acidosis, pseudohypoaldosteronism type 1. Nat Genet 1996, 12:248-253.

86. Hansson JH, Nelson-Williams C, Suzuki H, Schild L, Shimkets R, Lu Y, Canessa C, Iwasaki T, Rossier B, Lifton RP: Hypertension caused by a truncated epithelial sodium channel $\gamma$ subunit: genetic heterogeneity of Liddle syndrome. Nat Genet 1995, 11:76-82.

87. Hansson JH, Schild L, Lu Y, Wilson TA, Gautschi I, Shimkets R, NelsonWilliams C, Rossier BC, Lifton RP: A de novo missense mutation of the beta subunit of the epithelial sodium channel causes hypertension and Liddle syndrome, identifying a proline-rich segment critical for regulation of channel activity. Proc Natl Acad Sci USA 1995, 92:11495-11499.

88. Medway W, Geraci JR: Blood chemistry of the bottlenose dolphin (Tursiops truncatus). APS-Legacy Content 1965, 209:169-172.

89. Koopman HN, Westgate AJ, Read AJ, Gaskin DE: Blood chemistry of wild harbor porpoises Phocoena phocoena (L.). Mar Mammal Sci 1995, 11:123-135.

90. Ortiz RM: Osmoregulation in marine mammals. J Exp Biol 2001, 204:1831-1844

91. Kjeld M: Salt and water balance of modern baleen whales: rate of urine production and food intake. Can J Zoo 2003, 81:606-616.

92. Birukawa N, Ando H, Goto M, Kanda N, Pastene LA, Nakatsuji H, Hata H, Urano A: Plasma and urine levels of electrolytes, urea and steroid hormones involved in osmoregulation of cetaceans. Zool Sci 2005, 22:1245-1257.

93. Hoelzel AR: Molecular Genetic Analysis of Populations: A Practical Approach. Oxford: IRL Press; 1992

94. Thompson JD, Higgins DG, Gibson TJ: CLUSTAL W: improving the sensitivity of progressive multiple sequence alignment through sequence weighting, position-specific gap penalties and weight matrix choice. Nucleic Acids Res 1994, 22:4673-4680

95. Tamura K, Peterson D, Peterson N, Stecher G, Nei M, Kumar S: MEGA5: molecular evolutionary genetics analysis using maximum likelihood, evolutionary distance, and maximum parsimony methods. Mol Biol Evol 2011, 28:2731-2739

96. Nikaido M, Rooney AP, Okada N: Phylogenetic relationships among cetartiodactyls based on insertions of short and long interspersed elements: hippopotamuses are the closest extant relatives of whales. Proc Natl Acad Sci USA 1999, 96:10261-10266.

97. Agnarsson I, May-Collado LJ: The phylogeny of Cetartiodactyla: the importance of dense taxon sampling, missing data, and the remarkable promise of cytochrome $b$ to provide reliable species-level phylogenies. Mol Phylogenet Evol 2008, 48:964-985.

98. Xiong Y, Brandley MC, Xu S, Zhou K, Yang G: Seven new dolphin mitochondrial genomes and a time-calibrated phylogeny of whales. BMC Evol Biol 2009, 9:20.

99. Zhu K-L, Zhou X-M, Xu S-X, Sun D, Zhou K-Y, Yang G: Data from The loss of taste genes in cetaceans. Dryad Digital Repos 2014, http://dx.doi.org/ 10.5061/dryad.7qp63

\section{doi:10.1186/s12862-014-0218-8}

Cite this article as: Zhu et al:: The loss of taste genes in cetaceans. BMC Evolutionary Biology 2014 14:218. 